\title{
Pragmatics in the Post-TESL Certificate Course "Language Teaching for Employment"
}

Joan Bartel

For those immigrants to Canada who need some language training in order to access employment in their field, occupational ESL classes have been available in Ontario for several years. Recent additions to Occupation-Specific Language Training and Bridging programs, as well as a new emphasis on work-related content in LINC classes, have created a need for trained instructors for this area of ESL. The Language Training for Employment (LTE) is a Post-TESL Certificate course that addresses this need. Within the course, Pragmatics is 1 of 12 unitsone that participants have little knowledge of or practice with before the course, and 1 of 2 units that receive unanimously positive feedback from participants at the end. This article explains the conceptual framework of LTE, the content of the Pragmatics Unit, its implementation and participant feedback.

L'Ontario offre, depuis plusieurs années, des cours professionnels d'ALS aux immigrants canadiens qyant besoin de formation linguistique avant d'accéder à un emploi dans leur domaine. Des ajouts récents aux cours de formation linguistique axés sur des métiers précis et au programme de formation relais, de même que l'accent renforcé sur le contenu spécialisé dans les cours de langue pour les immigrants au Canada, ont créé un besoin pour des enseignants formés dans ce domaine d'ALS. La formation linguistique axée sur l'emploi (Language Training for Employment, LTE) est un cours sanctionné par un certificat qui vise ceux qui ont déjà une formation en enseignement de l'ALS et qui vient répondre à ce besoin. La compétence pragmatique constitue une des 12 unités; celle-ci représente un domaine largement inconnu des participants avant le cours, ainsi qu'une des 2 unités pour lesquelles les participants donnent, sans exception, des réactions positives à la fin du cours. Cet article explique le cadre conceptuel de la formation linguistique axée sur l'emploi, le contenu de l'unité portant sur la compétence pragmatique, la mise de en cuvre de celle-ci et la rétroaction de la part des participants.

\section{Conceptual Framework for Language Training for Employment (LTE)}

\section{Background to the Project}

Canada welcomes roughly 250,000 immigrants every year, with the largest contingency landing in Ontario. Language barriers often stand in the way of those seeking employment. Citizenship and Immigration Canada has re- 
sponded to the needs of these immigrants by funding employment-related language training at Canadian Language Benchmark Stages II-III (intermediate to advanced). Programs such as Enhanced Language Training (ELT), which is English as a second language (ESL) with additional job search training and usually a mentor or workplace internship, have existed for some years in Ontario, delivered by settlement and immigrant services agencies. More recently, Citizenship and Immigration Canada has worked with Colleges Ontario to develop and fund Occupation-Specific Language Training (OSLT) and Bridging programs for certain professional and technical occupations in which the colleges have expertise.

Typically, TESL Certificate programs do not address employment-related communication to any great extent in their 100 or even 250 hours of theory and methodology (TESL Canada Federation, 2012, pp. 10-11; TESL Ontario, 2013, pp. 8-9, respectively). But with the emergence of ELT, OSLT, and Bridging programs and the addition of work and job search content to general ESL classes such as Language Instruction for Newcomers to Canada (LINC), a need was created for experienced instructors who could address those specific language and communication issues. "Language for the workplace" was found to be a top priority when TESL Ontario explored professional development gaps in 2010-2011 (TESL Ontario, 2011b). The association fostered several initiatives for professional, post-TESL certificate training for ESL instructors, who were eligible for a TESL Ontario Certificate of Recognition upon successful completion.

In response to the perceived need, a post-TESL certificate training (PTCT) course, "Language Training for Employment," was developed under the auspices of TESL Ontario (see Bartel \& Beletzan, 2011). Taking into consideration the content of TESL programs in general (based on expertise and teaching experience in two respected TESL programs) and the practical English for Specific Purposes (ESP) teaching experience of this author (including ELT and OSLT from the pilot stage), four key components of a post-TESL certificate "Language Training for Employment" (LTE) course were identified:

- Language, building on teaching skills gained in initial TESL training, as well as ESL instructors' expertise and experience

- Context, situated in the areas of job preparation and specialized job search, reflecting the primary motivation and goals of learners in an LTE course

- Content, grounded in the workplace focus of LTE and the backgrounds of the learners

- Culture, including both general Canadian workplace and sector-specific cultural norms, behaviours, and practices. (Bartel \& Beletzan, 2011, p. 5)

\section{Identification of the Need for the Inclusion of Pragmatics in PTCT}

Language for successful communication at work, as elsewhere, depends not only on vocabulary, grammar, and the four skills, but also on appropriate- 
ness. Practicing instructors have long been aware of the negative effects of communication that is grammatically correct yet inappropriate, which can occur with nonnative-or native-speakers. The linguistic field that encompasses the study of situational appropriateness of language and nonverbal communication - speech acts - is pragmatics. While this field is a component of some TESL programs around the world - for example, in individual programs in Australia and India and in the great majority of MA programs in the United States - it is often offered as an elective or included piecemeal within other topics (Vásquez \& Fioramonte, 2011; Vásquez \& Sharpless, 2009). The study of pragmatics is also not currently a significant component of most TESL programs in Ontario. For that reason, it has recently been awarded an important place in post-TESL training (Bartel \& Beletzan, 2011; Klassen \& Priven, 2011).

\section{Pragmatics and Soft Skills in LTE}

A classic definition of pragmatics is

the study of language from the point of view of users, especially the choices they make, the constraints they encounter in using language in social interaction, and the effects their use of language has on other participants in the act of communication. (Crystal, 1985, p. 364)

One of the main resources of the LTE course, Tatsuki and Houck's Pragmatics: Teaching Speech Acts (2010b), uses this definition. The authors follow it with explanations of some foundational research in the field, which are quoted here as bullet points:

- linguistic strategies (often categorized in terms of level of directness) ...

- the modifiers that can be used to soften or intensify the act ...

- sequential management of the act ...

- the effects of social factors such as distance or power relationships ...

- and the degree of imposition or difficulty involved in performing the act. (p. 1)

Although the linguistic descriptions are helpful to us language instructors, they are not clear to employers in the hiring world. There the term soft skills has immediate recognition. An emerging trend in job postings is to list soft skills, or the related "interpersonal" or "people skills," as a job requirement for customer service roles and many management positions. While the definition of soft skills has not yet crystallized-multiple interpretations can be found online, for example-for the purposes of the LTE course they can be defined as "self-awareness and cultural awareness as well as interpersonal skills, including verbal and nonverbal communication, that follow or reflect expected polite behaviour, especially in the business or workplace context" (Bartel, 2012). 
The terms "soft skills" and "pragmatics" share common ground. The polite behaviour in the definition of soft skills is explicitly referred to in the description of pragmatics studies in terms such as "directness," "soften," or "social factors." The workplace is certainly a context in which job-seeking ESL learners want to become more aware of "the effects their use of language has on other participants in the act of communication" (Crystal, 1985, p. 364). Therefore, LTE participants learn that, when teaching pragmatics, they should embed the language in work and job search contexts, where they can often successfully explain their points to learners in terms of employment-related soft skills. This is important because knowledge and practice in meeting communication requirements for jobs in Canada is one of the main goals of those learners. Language acquisition is most successful when the learning material is not just "interesting" or even "motivating," but "compelling" (Krashen, 2011). In fact, even in mainly academically oriented TESL classes, Vásquez and Fioramonte (2011) reported that the students (future ESL instructors) were impressed by the power of examples of pragmatics in employment contexts:

[A] dominant theme that we identified in our data was that the assignments and texts that often made the strongest impression on students were those that were in some way "authentic," or that explained something about how pragmatics operates in the "real world" (i.e., in non-educational contexts). For example, ... between Japanese and American business people.... In particular, these texts and activities helped illustrate, in powerful ways, how pragmatic failure can have concrete and serious real-world repercussions. (pp. $13,15)$

Pragmatics should be a significant component of employment-related ESL and is thus a unit in LTE.

\section{The Role of Pragmatics in the Curriculum}

\section{LTE Content: Units to Be Covered}

Four clusters of topics were conceptualized by the curriculum authors: (a) the four language skills in the LTE context, (b) job search and work culture, (c) occupational content/terminology, and (d) pragmatics, corresponding to the four key components of the LTE course (Bartel \& Beletzan, 2011). The units are

Day 1

- Orientation to LTE Curricula

- LTE Content Focus: Sector-Specific Terminology in Job Postings

- Building Job Search Strategies into the LTE Curriculum 1: Job Search Terminology 
Day 2

- Building Job Search Strategies into the LTE Curriculum 2: Job Interviews

- LTE Language Skills Focus: Speaking and Listening

- The Instructor's Role in LTE: Pedagogical Approach

Day 3

- LTE Language Focus: Introduction to Pragmatics

- Workplace Culture in the LTE Curriculum

Day 4

- LTE Content Focus: Sector-Specific Terminology-Teaching as a NonExpert

- LTE Language Skills Focus: Reading and Writing

- Grammar and the LTE Curriculum

Day 5

- Summary: Balancing Language Accuracy, Pragmatics, and Content

- Developing a Community of Practice for LTE

Thus the curriculum starts with job search topics, an area of concern or interest to fully $50 \%$ of participants, according to a survey on Day 1 ; this should support and strengthen their decision to have enrolled. Next, pragmatics and workplace culture combine two exciting new areas to keep participants engaged. The four language skills are interwoven with high-interest topics: Speaking and Listening with Interviewing, and Reading-Writing-Grammar with Sector-Specific Texts (at 75\%, the topic of most common concern among participants). Finally, participants discuss balancing the traditional skills, in which they have general ESL experience, with the new workplace topics/ content and speech acts, leaving them ready to continue sharing their tips in a community of practice, in this case, an online group (within $<$ www.tutela. ca>) created by and for course graduates.

The LTE curriculum comprises 25 hours, delivered over five Saturdays. Experienced ESL instructors with a TESL Certificate were targeted as participants, as per TESL Ontario stipulations (TESL Ontario, 2011a, p. 10), course flyer (Appendix 2), and online course descriptions.

\section{Texts for the Pragmatics Unit}

The main resources for theory and practice combined are

- Center for Advanced Research on Language Acquisition (CARLA):

- What is a speech act? (CARLA, 2013)

- Introduction to pragmatics (the first seven screens), in Dancing with words (CARLA, 2010)

- Tatsuki and Houck's (2010b) Pragmatics: Teaching Speech Acts:

- Excerpts from Chapters 1 and 2, and one entire, individually assigned chapter. 
These materials are written by recognized experts in the field and include an excellent blend of theory and practice, ideal for PTCT. The free CARLA websites are interactive and allow participants to explore the concept of speech acts as well as samples of pragmatics activities in a nonthreatening (ungraded) way, with access to suggested answers at the click of the mouse. The readings in Tatsuki and Houck (2010b) are more academic. An excerpt from Chapter 1 (pp. 1-2) gives definitions and briefly summarizes research studies. The other chapters, one of which is assigned randomly to each participant, each present a speech act, beginning with theory and then providing actual lesson plans-mostly for English for Academic Purposes (EAP) settings. Course participants were not required to read further primary literature.

For the main assignment, participants have to substantially adapt those sample activities to fit the LTE setting. However, many participants lack experience with employment-oriented classes and may find the task difficult. To address this problem, two resources that place speech acts within the employment context are central to the activities:

- The freely accessible, employment-oriented Chapter 6 of Tatsuki and Houck (2010b): Yates and Springall's (2010) "Soften up! Successful requests in the workplace." This is the required text for the preparatory summary assignment.

- Bartel (2010), Office Soft Skills 2: How to Get Along and Get Ahead in Your Career. This textbook is replete with speech acts and other soft skills for newcomers to Canadian work culture. Material from Office Soft Skills is also incorporated into LTE in-class activities in the units on Canadian Workplace Culture and Writing. In this required textbook, participants are assigned a small, employment-related section that supports the speech act from their Tatsuki and Houck (2010b) chapter to use as they wish in their lesson plan.

\section{Assessment of Learning in the Pragmatics Unit}

To meet TESL Ontario's standards, "at least one of the graded assignments appraises the participant's ability to apply knowledge and skills gained during training to classroom practice" (TESL Ontario, 2011a, p. 11). To plan and teach a pragmatics lesson was the more heavily weighted of two major graded assignments. The lesson should be based on a handout of a pragmatics lesson plan template (see Appendix 1) as well as the speech act and corresponding activities described in the participant's individual chapter of Tatsuki and Houck (2010b). The objective is to enable participants to apply pragmatics theory specifically to the teaching of workplace communication.

This assignment constitutes $40 \%$ of the grade for the course: the lesson plan itself $(20 \%)$, and the reflective account of the mini-teaching session 
(20\%). The mini-teaching session itself does not receive a numerical mark (see below). The lesson plan is assessed according to its clarity and structure, its appropriateness for an LTE class, and the application of pragmatics theory to the classroom. The reflection assessment is based on comments on the lesson's effectiveness, learners' reactions, and the participant's own feelings and self-assessment.

The mini-teaching session (practicum) is

a necessary component of the assignment and must be completed for the assignment to be graded; the teaching component is to be assessed as Pass-Fail. The classroom context need not be an actual ESL class (LINC, EAP, ESP, Adult ESL, English in the Workplace, etc.) if the participant has no recourse to one. Since the lesson focuses on "pragmatics appropriate to an SLTE program" and it is assumed that no participant is already an expert in this field, a customized option of a simulated class with other PTCT participants in the role of students may be conducted. (Bartel \& Beletzan, 2011, p. 19)

Originally this major assignment, like a capstone project, concluded the pragmatics section of the course. After the pilot run, additional integrative activities involving pragmatics were added to the curriculum, especially in Day 5 (see below).

\section{Implementing the Pragmatics Unit in the Final Curriculum}

\section{Introduction to Pragmatics: Preparatory Assignment}

Participants work through the required CARLA material independently. Questions soliciting written responses are assigned for Tatsuki and Houck's (2010b) Chapters 1 and 2. In addition, participants summarize and write a reflection on Yates and Springall's "Soften Up!" (2010). Thus participants come to class with knowledge of basic pragmatics concepts and lesson activity examples.

This homework is vital because, in fact, it was found that participants knew very little about the field. A harbinger came on the first day of the pilot class, when participants were asked to note units that dealt with topics they were concerned about or particularly interested in. (The objective was to stimulate reflection on their own goals for the course as well as give the trainer some insights into needs.) No participant mentioned being concerned about the pragmatics aspect of LTE. Results were only slightly better for the second cohort of participants. This lack of concern or interest, unfortunately, did not mean that all participants were comfortable with and knowledgeable about speech acts; on the contrary, it was evidence of little exposure to them. 


\section{Introduction to Pragmatics: Classroom Procedure}

On Day 3, when the unit Introduction to Pragmatics is presented, participants first discuss the homework. Then they play the role of learners and follow the trainer's lead as she delivers a lesson on pragmatic competence (an adaptation of a chapter from Houck \& Tatsuki, 2011; any chapter could be used) involving several language skills within a workplace communicative situation. Activities within that role-play include writing responses, listening (to a tape and to live conversations), practicing intonation, and pair dialoguing. Participants are allowed time for reflection, and then the class discusses the activity and their reactions to it. Elements of a pragmatics lesson plan are elicited, from the warm-up/contextualization stages - which in pragmatics are closely linked to the awareness-building stage - to the assessment stage, and a template is distributed (Appendix 1). The trainer-led model and lesson plan template form the basis for the participants' assignment: to write and teach their own pragmatics lesson plan, based on a chapter of Tatsuki and Houck (2010b) and an excerpt from Bartel (2010). As class time permits, participants begin work on this assignment, brainstorming or discussing with a partner what they might include in their mini-practicum. Altogether, in-class activities include group and whole-class discussion of theory and methodology, brief individual reflection time, role-playing using various skills as the trainer models a lesson, and pair discussion/brainstorming.

Later that day, the unit Workplace Culture in the LTE Curriculum is introduced. Among other activities, a connection is made to pragmatics through soft skills, or "invisible" Canadian workplace culture, as participants seek, almost in vain, for examples of it in LTE-appropriate textbooks. The experience supports the findings of an important analysis of ESL/EFL textbooks, namely, that very little pragmatics material is presented there (Vellenga, 2004). As well, in this unit it is stressed that the "workplace" should not be overgeneralized. One LTE participant, when discussing her materials with some native speaker TESL students, found that

we disagreed on what was "typical" in the Canadian workplace.

While this highlighted [some] variables in the types of interactions in the workplace, and the variation in personal opinion on these issues, I had to ... emphasize the importance of referring to research findings instead of relying on personal experience or intuition.

Instructors explain pragmalinguistic strategies and learners practice them because immigrants, in the words of two authors of employment-related ESL materials,

need to be made aware that each organization has its own corporate culture regarding formality and informality, and therefore they need to be prepared to adopt the norm of the business in which they are participating. (Yates \& Springall, 2010, p. 71) 
However, it is also imperative that instructors not force these strategies on immigrants. Armed with an awareness and understanding of native speaker communication skills, they are then empowered to make choices. As one engineer from the Netherlands stated:

I like living in Canada ... But one thing that has always bothered me is that Canadians will not tell you what they think ... They have a hard time dealing with open and honest comments. Each year during annual performance review at my company, managers tell me that I'm too blunt and that I need to be more diplomatic in the way I speak. Well, I am not a diplomat. I am an engineer and this is who I am. I'm not going to start diluting my message just because of some oversensitive Canadians. (Laroche \& Rutherford, 2007, p. 142)

\section{Pragmatics Unit: Assessment of Participants in the First Two Cohorts}

Two sessions of LTE have taken place-October-December 2012 and February-March 2013; as of this writing, a third course is running. The pilot had 9 enrollees and the second session 18 (the third cohort of 9 is not part of the results reported here). The participants had a wide range of ESL teaching experience, from several years of ongoing employment-related ESL to little recent teaching beyond tutoring or supply teaching (some had clearly interpreted the term "experienced ESL teacher" optimistically for themselves). Not surprisingly, the result was a range of grades for the pragmatics unit graded assignment, with a small minority scoring very low on first submissions but altogether a strong average in the 80th percentile for both cohorts.

On the graded assignment, participants' weaknesses were generally in writing lesson plans rather than in misapplying pragmatics. Some participants had simply not activated knowledge from their TESL program for a long time; for others, lesson plans required on the job did not need the same amount of detail. Problematic areas included, for example, a lack of understanding or labelling of lesson plan stages and too little detail. However, the awareness-building stage, especially important for a pragmatics lesson, was not often neglected, perhaps because it represented new material on which participants realized they should focus, and because it was also usually identified in the Tatsuki and Houck (2010b) text. Understanding and applying pragmatics to the classroom setting was also evident in most assignments, although that setting was sometimes not, or not adequately, employmentrelated.

For the lesson plan alone, participants' marks averaged 71\% in the first cohort, where the assignment was the initial graded assignment, and a stronger $84 \%$ for the second cohort, where it was the second graded lesson plan. As is implied in these numbers, in both sessions most participants' lesson plan writing skills improved significantly during the course. 
The reflective accounts on the mini-teaching sessions were thoughtful and showed a genuine interest in the pragmatics assignment and the learning experience. They generally earned high marks. Enthusiastic language like "delighted" and "really enjoyed" was used to describe the practicum experience. (In the following sections, participants are quoted anonymously.) For this assignment, the effectiveness of the instruction, or learner success, was not strictly measured but often recounted in terms of learners' use of the lesson's speech act during and even after class. In the most positive case:

I could tell that students learned what I had intended because they became progressively more familiar and comfortable with incorporating these modifiers in their dialogues (even during the following days in class).... One ... student said "the lesson made me think about my own first language strategies and, in comparison, how to change them to properly 'fit' in a Canadian workplace environment"; other students concurred.

Several others, particularly those who did not do the practicum in their own ESL class, expressed concern about the lasting effectiveness of the lesson. As one participant noted, "My experience shows that students have to accept the pragmatics mentally and practice a lot till the process becomes automatic." Learners were usually aware of this, as well; for example, one student after a lesson on disagreeing politely, "jokingly said that he will now disagree with everybody so that he could practice using what he had learned." On the other hand, learners in one classroom became overly polite after their lesson, so that the practicum teacher then "provided them with alternative scripts for various situations," further raising their awareness of the sociocultural environments for the use of "please."

In their reflections, virtually all participants commented that they would make changes if they taught the lesson again. The most common change related to time management. Most participants had not foreseen the amount of discussion that was engendered, usually during the contextualization or awareness phase, which "created an atmosphere of curiosity and interest," during which time the learners were engaged in a truly compelling speaking activity. (Others shared their lesson with colleagues or native-speaker TESL students and found that those groups also got caught up in the topic, as mentioned above with regard to workplace culture.)

After the practicum, a few thoughtful participants reflected on previous teaching moments. For example, looking back on a situation in which one learner's habit of borrowing papers from others created a disharmonious atmosphere in class, a participant contrasted her previous grammar-based action with her new insights:

I taught this lesson using Can and May. Unfortunately what I missed was that the ... students were missing the pragmatic awareness. It 
was only after reading and reflecting on this chapter did I realize that it was a question of "misfires," in that what was lacking was the sociocultural component.... I am now more aware of the importance of incorporating this lesson [of softening requests] at every level.

Most participants looked forward to including speech acts in their future classes, summed up by one as follows:

Teaching this pragmatics lesson ... taught me a lot about the value of this information for students looking to enter the North American workplace. [Among] my students ... there is a lot of variation when it comes to grammar needs, pronunciation needs, and so on. But what all of my students have in common is the need to learn North American cultural norms. This would be helpful to the entire group, especially when it comes to helping them "fit in" in the Canadian workplace.

The data from the first two LTE sessions are too limited to draw conclusions about the effects of a variety of variables (e.g., experience teaching at CLB Stage II) on grades. However, it does show that the participants' first language (English or other) was not a predictor of success.

\section{Integrative Activities on the Concluding Day}

To recycle and recap on the final class day, two activities required participants to consider competencies in pragmatics, the four language skills, and grammar. Thus all the units are integrated, reflecting the mixture of language used in real-life conditions. These activities are

1. a homework assignment in preparation for Day 5 that requires participants to suggest a pragmatics activity, as well as skills activities, for a lesson on interviewing and a lesson on e-mail writing, based on immigrants' experiences described in the required text by Laroche and Rutherford (2007).

2. an in-class activity that was inspired by a recent article, Hong and $\mathrm{Wu}$ (2013), which reports how instructors evaluate learners' utterances on the basis of accuracy in grammar vs. pragmatics. Their sample utterances were adapted for the LTE course, and the pragmatics aspect added to the discussion of weighting grammatical accuracy and fluency, a topic with which ESL teachers are familiar. This activity also addresses in part a topic that a few participants identified as being of concern to them at the beginning of the course: assessment issues.

\section{Participant Feedback and Reflection}

Participants' anonymous postcourse feedback forms, handed out and collected on the final day of class, showed enthusiasm for all 10 units of LTE. On a scale of 1 (not useful) to 3 (very useful), participants were unanimous in giv- 
ing the Pragmatics Unit, as well as the unit on Canadian Workplace Culture, the highest rating, 3.0. The other eight units averaged 2.8-2.9, that is, they were rated very useful by $75-91 \%$ of the participants.

While the Canadian Workplace Culture unit is specific to an LTE context, several participants pointed out that pragmatics can be introduced into any ESL class, thereby becoming immediately applicable to any teaching situation. In postcourse communications, two participants commented that they had incorporated some of their lesson plan and course insights into classes they were currently teaching; only one of those classes was in an LTE context. Detailed information about the transfer of pragmatics knowledge and teaching strategies into their actual teaching practice is not available for these cohorts. The need for more study in this area is recognized by those in the field. Research results by Vásquez and Fioramonte (2011) illustrate a similar enthusiasm for their new pragmatics knowledge among MA TESL graduates, while also pointing to the difficulty instructors experience in finding time to teach speech acts within a given curriculum:

While some of our participants made pragmatics part of their lessons, the majority instead seemed to address pragmatics "as it came up" with their students... [E]ven though they identified pragmatics as a need that their ESL students had, they were not always able to adequately address those needs. In this respect, curricular constraints represented the primary challenge, followed by lack of suitable and relevant instructional materials. (Vásquez \& Fioramonte, 2011, p. 16)

Fortunately, over the past few years, there has been an increase in relevant instructional materials, including the successful lesson plans for teaching various speech acts in ESL classes (piloted mostly in EAP contexts) provided in Tatsuki and Houck (2010b).

With regard to pragmatics and soft skills for Canadian work culture, it was clear to the LTE trainer that participants without much work experience here-mostly recent arrivals (within 1.5-2.5 years) to Canada-were essentially in the same situation as their ESL learners, in that they were largely unaware of Canadian expectations. They often expressed this insight themselves: the course opened her eyes to a "whole new world," one exclaimed in class. A couple of participants said they would share their new knowledge with a family member who was job-hunting. Another (who had several years of Canadian work experience) reflected:

I also learnt that being an immigrant myself I do make some pragmatic errors now and then, and the readings and lesson plan preparation enhanced my own awareness and sensitivity to this important aspect of interaction in the Canadian job market. 
Some of the TESL students in Vásquez and Fioramonte's (2011) study made similar observations "about how the course stimulated awareness of their own culturally-informed ways of communicating" (pp. 15-16).

The course texts were also appreciated: Tatsuki and Houck (2010b) and Bartel (2010) were given the highest (useful) of three ratings by $87 \%$ of LTE participants. In written comments the adverbs "extremely" and "very" were used for both books, and Tatsuki and Houck (2010b) was called "an eyeopener" and "insightful." The CARLA website was top-rated as useful by $80 \%$, although one participant found it repetitious. No one rated any of the pragmatics (or other) texts as Not really useful. In answer to the question "Do you feel that this program has helped to prepare you to teach in LTE programs?" all participants answered "Yes."

\section{Conclusion}

Research into the extent of pragmatics content as a component in Canadian TESL Certificate programs is not available. As a consequence, the writers of this Pragmatics Unit have grounded it in a mix of both theory and practice. To summarize, the feedback on the content and usefulness of the Pragmatics Unit was conclusively positive: both the trainer and the participants, whether experienced in employment-related ESL or not, unanimously expressed a high satisfaction level with the content and results. The unit proved immediately applicable to the LTE context as well as other ESL class settings. For all involved, the course provided inspiration for further study of this field and future interactions with peers. Further research into the extent of the transfer of knowledge and practice into their ESL classrooms by graduates of post TESL certificate training courses such as LTE would be welcome enrichments to the field.

\section{Acknowledgements}

I would like to thank the participants of my Language Training for Employment classes at Humber College Institute of Technology and Advanced Learning for permission to quote from their papers.

\section{The Author}

Joan Bartel has been active in ESLIEPL teaching, textbook/curriculum writing, program administration, and TESL training, and is currently working in the TESL and Occupation-Specific Language Training programs at Humber College, Toronto. With an MA in Language Teaching and Career Counselling certificates, she presents frequently on soft skills and immigrants' communication needs for employment.

\section{References}

Bartel, J. (2010). Office soft skills 2: How to get along and get ahead in your career. Toronto, ON: Author. 
Bartel, J. (2012, March). Teaching soft skills within ESL/ESP: What, why, how. Paper presented at the 2012 international convention of TESOL, Philadelphia, PA.

Bartel, J., \& Beletzan, V. (2011). Specialized language training for employment (SLTE). In Framework for post TESL certificate training. Toronto, ON: TESL Ontario. Retrieved from http:// www.teslontario.net/uploads/accreditation/PTCT/HumberCollege.pdf

Center for Advanced Research on Language Acquisition (CARLA). (2010). Introduction to pragmatics. Minneapolis, MN: University of Minnesota. Retrieved from http://www. carla.umn.edu/speechacts/sp_pragmatics/Introduction_to_pragmatics/introduction_to_ pragmatics.html

Center for Advanced Research on Language Acquisition (CARLA). (2013). Pragmatics and speech acts. Minneapolis, MN: University of Minnesota. Retrieved from http://www.carla.umn.edu/ speechacts/index.html

Crystal, D. (1985). A dictionary of linguistics and phonetics. Oxford, UK: Blackwell.

Hong, C.-Y., \& Wu, Y.-G. (2013, March). EFL teachers' pragmatic evaluation of learners' facethreatening acts. AL Forum: The Newsletter of the Applied Linguists Interest Section (TESOL). Retrieved from http://newsmanager.commpartners.com/tesolalis/issues/2013-03-07/index. html\#story

Houck, N. R., \& Tatsuki, D. H. (Eds.). (2011). Pragmatics: Teaching natural conversation. Alexandria, VA: TESOL.

Klassen, B., \& Priven, D. (2011). Higher level language training for internationally trained professionals and skilled workers at stage II/III (CLB 8-10). In Framework for post TESL certificate training. Toronto, ON: TESL Ontario. Retrieved from http://www.teslontario.net/ uploads/accreditation/PTCT/AlgonquinCollege.pdf

Krashen, S. (2011). The compelling (not just interesting) input hypothesis. The English Connection, 15(3), IC1. Retrieved from http://koreatesol.org/sites/default/files/pdf_publications/ TECv15n3-11Autumn.pdf

Laroche, L., \& Rutherford, D. (2007). Recruiting, retaining, and promoting culturally different employees. Burlington, MA: Butterworth-Heinemann (Elsevier).

Tatsuki, D. H., \& Houck, N. R. (2010a). Pragmatics from research to practice: Teaching speech acts. In D. H. Tatsuki \& N. R. Houck (Eds.), Pragmatics: Teaching speech acts (pp. 1-6). Alexandria, VA: TESOL.

Tatsuki, D. H., \& Houck, N. R. (Eds.). (2010b). Pragmatics: Teaching speech acts. Alexandria, VA: TESOL.

TESL Canada Federation. (2012). TESL Canada Federation teacher training program standards. Retrieved from http://www.tesl.ca/media/1670/rttp_explanation_standards_and_form.pdf

TESL Ontario. (2011a). Framework for post TESL certificate training. Toronto, ON: Author. Retrieved from http://www.teslontario.net/uploads/accreditation/PTCT/TESL_Ontario_Framework_ for_Post_TESL_Certificate_Training_2011.pdf

TESL Ontario. (2011b). New: A list of the FPTCT priority content areas. In Framework for post TESL certificate training. Toronto, ON: Author. Retrieved from http://www.teslontario.ca/ framework2010/news.html\#Launch

TESL Ontario. (2013). Institutional accreditation application (for TESL training programs). Toronto, ON: Author. Retrieved from http://www.teslontario.net/uploads/accreditation/Institutions/ InstitutionalAccred.Guide.pdf

Vellenga, H. (2004). Learning pragmatics from ESL \& EFL textbooks: How likely? TESL-EJ, 8(2), $1-18$.

Vásquez, C., \& Fioramonte, A. (2011). Integrating pragmatics into the MA-TESL program: Perspectives from former students. TESL-EJ, 15(2), 1-22.

Vásquez, C., \& Sharpless, D. (2009). The role of pragmatics in the Master's TESOL curriculum: Findings from a nationwide survey. TESOL Quarterly, 43(1), 5-28.

Yates, L., \& Springall, J. (2010). Soften up! Successful requests in the workplace. In D. H. Tatsuki \& N. R. Houck (Eds.), Pragmatics: Teaching speech acts (pp. 67-88). Alexandria, VA: TESOL. 


\section{Appendix A \\ Model Pragmatics Lesson}

In a student-centred language classroom, pragmatics, like vocabulary and grammar, should be taught in response to students' communicative needs. Lessons are based on students' contexts, interests, goals, and backgrounds/ experiences. In LTE classes, students' contexts, goals, backgrounds, and so on are occupation-specific.

Typically, vocabulary and grammar are more frequently addressed than pragmatics in the language classroom-due in large part to a greater focus on the former in entry-level TESL programs. The Pragmatics books edited by Tatsuki and Houck (2010a, 2010b) help fill this gap by offering examples and discussion of effective teaching materials.

In a Pragmatics lesson plan for LTE, speech acts, by nature contextualized in situations, are introduced in real-life, occupational scenarios. In the Isolation stage, awareness-raising of the speech act is often a necessary step, accompanied by form-focused instruction. The speech act is explicitly explained through the use of examples taken from the Contextualization stage. Intonation, word stress, and tone of voice are addressed, and suggestions are made for modifications regarding register. The students' understanding is checked in the Verification stage. Finally, controlled and guided practice of the speech act occurs during the Practice stage.

Similar to a traditional grammar lesson plan, a Pragmatics lesson plan starts with objectives. Raising awareness of a speech act may be an integral part of the objective.

General Objective: is related to the topic of the lesson; e.g., "Students will become aware of and/or learn a variety of strategies to be able to refuse an invitation with appropriate politeness /softness."

Specific Objective: is specific to the speech acts being taught; e.g., "Students will be able to soften a refusal to an invitation by adding a reason, a positive statement, an alternative plan, an apology and/or a thanks to a direct refusal statement."

The following are possible stages (Awareness-raising can begin in any early stage):

1. Pre-Activity

- sets general "scene"

- uses background knowledge of students to predict content, giving them confidence and focus

- familiarizes students with new subject matter

- pre-teaches selected new vocabulary

- introduces relevant cultural aspects of the speech act, beginning to raise awareness 
2. Contextualization: Specific speech acts are contextualized or presented in a real-life situation, e.g., the instructor inviting each student to an office appointment at a specific time or "accidentally" bumping into a student.

3a. Isolation/Awareness: An awareness activity, often a discussion, may precede an explanation; e.g., the instructor might ask how the student felt when being asked to attend an office appointment at an unusual time, or when being accidentally bumped into without an apology.

3b. Presentation (form-focussed): Formal explanation: speech acts are explicitly explained through the use of examples taken from the contextualization; intonation, word stress, and tone of voice are addressed. Specific steps are followed in the explanation of new strategies or application of previously acquired strategies to new contexts.

3c. Verification: Students are asked to "quickly" verify their understanding of the new structures/functions or applications; error correction occurs at this point.

4. Practice Stage: This is the longest stage of the lesson. Students practice the speech acts through the progressive manipulation of materials and activities. Students may begin with controlled activities and work toward communicative or real-life activities; e.g., composing dialogues that include invitation refusals based on students' actual experiences in Canada.

Controlled Practice Activities:

- focus on specific forms and functions/strategies

- focus on accuracy

- error correction

Communicative Practice Activities:

- focus on fluency

- students use all structures/strategies taught up to this point

- students work on task and receive feedback

5. Wrap-up and Evaluation: Assesses students' attainment of the lesson objectives. 


\section{Appendix B \\ Language Training for Employment Course Description}

Language Training for Employment (LTE)

Course Description: The launch of new Language Training for Employment (LTE) programs such as Occupation-Specific Language Training (OSLT) has created an increasing need for qualified instructors with the knowledge and experience to teach the specific language and communication needs of immigrants preparing to enter the Canadian work force. This course builds on experienced ESL instructors' professional classroom skills and knowledge with training specific to the instructional context of employment-related programs such as OSLT, ELT (Enhanced Language Training), English for Nursing, and Business English. 